\title{
The Role of Erythropoietin in the Treatment of Anemia in Patients with Malignant Lymphoma
}

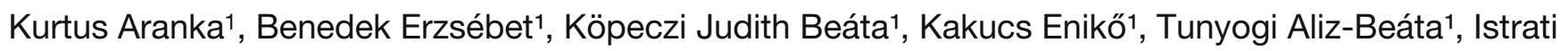 \\ Monica ${ }^{1}$, Benedek $\mathrm{I}^{2}$ \\ 1 Clinical Hematology and BMT Unit, County Emergency Clinical Hospital, Tîrgu Mureș, Romania \\ 2 University of Medicine and Pharmacy, Tîrgu Mureș, Romania
}

\begin{abstract}
Introduction: Anemia is a common complication of malignant lymphomas, which could be a direct consequence of the disease or secondary to the myelosupressive chemotherapy. The aim of this study was to assess the effect of erythropoietin to treat anemia. The main objectives were to demonstrate increases in hemoglobin levels and the existence of an association between symptom relief and treatment.

Material and method: In the Clinical Hematology and BMT Unit Tîrgu Mureș we performed an analytical, observational study to assess the role of erythropoietin treatment in malignant lymphoma related anemia. This linear, retrospective study included 127 patients diagnosed and treated with malignant lymphoma between January 1st, 2007 and December 30, 2011. The 127 patients were divided into two groups: a group of patients $(n=88)$ who were treated with erythropoietin and the other group $(n=39)$ who did not receive this treatment. Patients included in the study received treatment with epoetin beta 40,000 IU/week. We followed the hemoglobin level and the symptomatology at baseline and after 4 weeks.

Results: Patients who received treatment with erythropoietin had a 7.12 times higher possibility of being asymptomatic than patients who did not receive this treatment. The hemoglobin concentration of patients with erythropoietin treatment increased significantly $(p<0.0001)$ compared to the patients who did not receive this treatment.

Conclusion: Effective treatment of anemia is an important aim in the management of patients with malignant lymphomas, because it increases their hemoglobin concentration, decreases the need of transfusion and maintains an acceptable quality of life.
\end{abstract}

Keywords: malignant lymphoma, erythropoietin, anemia

Received: 5 May 2012

\section{Introduction}

Anemia is a common complication of malignant lymphomas, which could be a direct consequence of the disease or secondary to the myelosupressive chemotherapy $[1,2,3]$. This may be due to the reduction of erythropoesis, manifested by reduction of erythrocyte half-life, poor iron reutilization by the bone marrow and inadequate response to erythropoetin with reduced endogenous erythropoetin levels $[4,5,6]$. Anemia may have a significantly negative effect on the quality of life of patients suffering from malignant lymphoma, producing symptoms such as dizziness, fatigue, weakness, nausea, headache and depression [7].

The human erythropoietin is an acidic glycoproteinhormone with a 34,000 molecular weight synthesized mainly in the kidney by specialized cells and to a minor degree in the liver [8]. Tissue hypoxia triggers the synthesis and the release of erythropoietin into the blood. Erythropoietin is the primary regulator of human erythropoiesis and has two major functions: stimulating proliferation of erythroid progenitor cells and maintaining their viability by inhibiting their apoptosis [5,9]. In 1993, the use of erythropoietin was approved by the FDA for the treatment

Correspondence to: Aranka Kurtus

E-mail: kurtus.aranka@gmail.com of anemia in cancer patients. Three types of erythropoietin produced by recombinant DNA technology are used: epoetin alfa, epoetin beta, and darbepoetin $[8,10]$.

The aim of this study was to assess the effect of erythropoietin to treat anemia. The main objectives were to demonstrate increases in hemoglobin levels and the existence of association between symptoms relief and treatment, and the secondary objective was to evaluate the need of transfusion. We hypothesized that erythropoietin treatment increases hemoglobin levels in malignant lymphoma patients and improves the symptoms caused by anemia.

\section{Material and method}

We performed an analytical, observational study to assess the role of erythropoietin treatment in malignant lymphoma related anemia. For data collection we used preexistent medical records. This linear, retrospective study was carried out in the Clinical Hematology and BMT Unit of Tîrgu Mureș and included 127 patients diagnosed and treated with malignant lymphoma between January 1 1st, 2007 and December 30, 2011. Patients with the following criteria were included in the study: $\mathrm{Hb}<11 \mathrm{~g} / \mathrm{dl}$, serum ferritine level in normal limits and the transferrin saturation $>20 \%$, accusing dizziness, fatigue, weakness, nausea, headache and depression. Exclusion criteria were: patients who had other types of anemia with ferritine level below the lower 
Table I. Association between erythropoietin treatment and anaemia associated symptoms

\begin{tabular}{lccc}
\hline & $\begin{array}{c}\text { Symptoms } \\
\text { improved }\end{array}$ & $\begin{array}{c}\text { Symptoms } \\
\text { unchanged }\end{array}$ & Total \\
\hline Patients with treatment & 57 & 31 & 88 \\
Patients without treatment & 8 & 31 & 39 \\
Total & 65 & 62 & 127 \\
\hline
\end{tabular}

limit of normal reference range and other disorders that can cause the above mentioned complaints. The 127 patients were divided into two groups, established by the case-control model: a group of patients $(\mathrm{n}=88)$ who were treated with erythropoietin and the other group $(n=39)$ who due to objective or subjective reasons did not receive this treatment. Patients included in the study received treatment with epoetin beta 40,000 IU/week. We followed the hemoglobin level and the symptomatology at baseline and after 4 weeks.

The obtained qualitative values were introduced in a contingency table, in GraphPad InStat statistical programme and the Chi square test was performed and the results were supervised by the Fisher test. The quantitative, continuous variables have been subjected to a rigorous statistical analysis. Distribution normality was verified using continuous numeric variables Kosmogorov-Smirnov test. Differences between continuous quantitative variables which did not respect the condition of normality were further analyzed using the Mann-Whitney $U$ test for unpaired, non-parametric data. A value of $\mathrm{p}<0.05$ was considered statistically significant.

\section{Results}

In the studied groups men predominated, the men:women ratio was $1.2: 1$. The mean age of the patients was 60.24 years (range $34-76$ years).

Anemia was present in $33 \%$ of malignant lymphoma patients at the moment of diagnosis and in $67 \%$ of them it has developed during antineoplastic therapy.

Chi-square test: 19.453; Odds Ratio (OR): 7.12 (95\% CI 2.92-17.38), $\mathrm{p}<0.0001$. Fisher's exact test yielded the same results.

The mean hemoglobin level at baseline in the erythropoietin group $(\mathrm{n}=88)$ was $8.84 \mathrm{~g} / \mathrm{dl}(\mathrm{SD} 1.044,95 \% \mathrm{CI}$ : $8.597-9.040$ ) and in the other group it was $8.79 \mathrm{~g} / \mathrm{dl}$ (SD 1.035 , 95\% CI: 8.462-9.133). The difference was not statistically significant $(\mathrm{p}=0.8750)$.

We repeated the statistical analysis after four weeks of therapy with the following results: in the erythropoietin group $(\mathrm{n}=88)$ the mean hemoglobin level was $9.74 \mathrm{~g} / \mathrm{dl}$ (SD 1.090, 95\% CI: 9.516-9.976) and in the untreated group it was $8.81 \mathrm{~g} / \mathrm{dl}$ (SD $1.060,95 \% \mathrm{CI}: 8.500-9.187$ ). The difference was statistically significant ( $\mathrm{p}<0.0001$ ).

The proportion of patients receiving red blood cell transfusions during the study period was $15.90 \%$ in the erythropoietin group $(n=14)$ and $43.58 \%(n=17)$ in the control group. In the erythropoietin group 25 units of red blood cell were used, and 27 units in the control group.

\section{Discussions}

Anemia is frequent in cancer patients and its incidence increases with chemotherapy. In hematological malignancies, the prevalence of anemia is almost double than in solid tumors [11]. Neoplastic bone marrow infiltration and chemotherapy seem to play a major role in the pathogenesis of anemia associated with malignant lymphomas. According to other studies, an estimated $30-40 \%$ of malignant lymphoma patients are anemic at the time of diagnosis, with the incidence rising to $70 \%$ during chemotherapy [12]. This was confirmed by the results of the present study, which shows that anemia was present in $33 \%$ of the patients at the moment of diagnosis and in $67 \%$ of them it has developed during antineoplastic therapy. Malignant lymphomas promote inflammatory cytokine production, which suppresses erythropoesis and erythropoetin production [13]. Data from many studies indicate that treatment of anemic patients with erythropoesis stimulating agents improves erythropoiesis, increases the hemoglobin concentration, decreases the need of transfusion, and also improves their quality of life $[8,14,15,16]$. The obtained results show that the difference between mean hemoglobin level after four weeks after onset of therapy was extremely significant ( $\mathrm{p}<0.0001)$, and hemoglobin levels at week four ranged from $8.81 \mathrm{~g} / \mathrm{dl}(\mathrm{SD} 1.044)$ to $9.74 \mathrm{~g} / \mathrm{dl}$ (SD 1.090).

Anemia is a major reversible cause of cancer-related fatigue, has a negative impact upon the quality of life and is a negative prognosis factor regarding general survival $[13,17,18]$. Our study suggests that improving hemoglobin level may improve the patient's symptomatology caused by anemia. There are highly significant correlations between symptoms at 1 month after the treatment and the treatment applied $(p<0.0001)$. The possibility of being asymptomatic in patients who received treatment with erythropoietin is 7.12 times higher $(\mathrm{OR}=$ 7.12) than in patients who did not receive this treatment. Erythropoietin stimulating agents therapy is well tolerated, provides important clinical benefits for lymphoma patients with anemia by reducing the need for red blood cell transfusions and exposure to associated risks. Transfusions can cause many adverse reactions, like febrile non-hemolytic transfusion reaction, bacterial and viral infection, acute hemolytic reaction, anaphylactic reaction, transfusion associated acute lung injury, volume overload, iron overload, post transfusional purpura and delayed hemolytic reaction $[17,19,20]$. All this can be avoided if the severe anemia development is prevented with erythropoietin stimulating agents. In our study the proportion of patients receiving transfusions was significantly lower in the erythropoietin group than in the control group. Among patients who were treated with erythropoietin the median transfusion volume decreased 
considerably compared to the control group. Similar results have been reported by others in randomized recombinant human erythropoietin studies. These studies showed that early initiation of erythropoietin treatment can lead to a reduction in the costs associated with red blood cell transfusion [11,20,21].

\section{Conclusions}

Effective treatment of anemia is an important aim in the management of patients with malignant lymphomas, in order to maintain an acceptable quality of life. In patients with malignant lymphoma and anemia, erythropoietin increases hemoglobin levels, thus reducing the need for blood transfusion and improving the quality of life. Recombinant human erthropoietin is a promising therapeutic opportunity for treating malignant lymphoma associated anemia.

\section{References}

1. Bohlius J, Weingart O, Trelle S, Engert A. Cancer-related anemia and recombinant human erythropoietin - an updated overview. Nature Clinical Practice Oncology. 2006;3:152-154.

2. Nagy J, Kiss I. Az eritropoetin pleiotrop hatásai. LAM. 2007;17(12):861867.

3. Aapro M, Österborg A, Gascón P, Ludwig H, Beguin Y. Prevalence and management of cancer-related anaemia, iron deficiency and the specific role of i.v. iron. Annals of Oncology. 2012;23:1954-1962.

4. Bohlius J, Schmidlin K, Brillant C, et al. Erythropoietin or Darbepoetin for patients with cancer - meta-analysis based on individual patient data. Cochrane Database of Systematic Reviews 2009, Issue 3. Art. No.: CD007303. DOI: 10.1002/14651858.CD007303.pub2.

5. Barrett-Lee PJ, Ludwig H, Birgegård G. Independent risk factors for anemia in cancer patients receiving chemotherapy: results from the European Cancer Anemia Survey. Oncology. 2006;70:34-48.

6. Birgegård G, Aapro MS, Bokemeyer C. Cancer-related anemia: pathogenesis, prevalence and treatment. Oncology. 2005;68(Suppl 1): 3-11.

7. Thomas ML. Impact of anemia and fatigue on quality of life in cancer patients; A brief review. Med Oncol. 1998;15:53-57.
8. Shasha D, George MJ, Harrison LB. Once weekly dosing of epoetin $\alpha$ increases hemoglobin and quality of life in anemic cancer patient receiving radiation therapy either concomitently or sequentially with chemoterapy. Cancer. 2003;98:1072-1079.

9. Miller Carole B, Jones RJ, Piantados S, Abeloff MD, Spivak JL. Decreased Erythropoietin Response in Patients with the Anemia of Cancer, M.D. N Engl J Med. 1990;322:1689-1692.

10. Engert $A$, Josting $A$, Haverkamp $H$, et al. Epoetin Alfa in Patients With Advenced-Stage Hodgkin's Lymphoma. Results of the Randomized Placebo-Controled GHSG, HD15 EPO Trial. J Clin Oncol. 2010;28(13):22392245.

11. Spivak JL, Gascon P, Ludwig H. Anemia Management in Oncology and Hematology. The Oncologist. 2009;14(S1):43-56.

12. Coiffier B. Anemia associated with non-platinum chemotherapy (CT) for Hodgkin's lymphoma $(\mathrm{HL})$ or non-Hodgkin's lymphoma $(\mathrm{NHL})$. European Journal of Cancer. 1999;35:S331.

13. Campos MPO, Hassan BJ, Riechelmann R, Del Giglio A. Cancer-related fatigue: a practical review. AnnOncol. 2011;22(6):1273-1279.

14. Littlewood TJ. Erythropoietin for the treatment of anemia associated with hematological malignancy. Hematological Oncology. 2001;19(1):19-30.

15. Truong Pauline T, Parhar Tarnjit BS, Hart J, Alexander Cheryl, Wai Elaine S. Population-Based Analysis of the Frequency of Anemia and its Management Before and During Chemotherapy in Patients With Malignant Lymphoma. American Journal of Clinical Oncology. 2010;33(5):465-468.

16. Pirker R. Safety considerations for erythropoietin treatment in patients with cancer, Expert Opinion on Drug Safety. 2007;6(1):63-69.

17. Deger M, Eisterer W, Kutikova Lucie, Salek S. Hemoglobin level at initiation of darbopoetin alfa: impact on need for transfusion and associated costs in chemoterapy-induced anemia treatment in Europe. Supportive Care in Cancer. 2013;21:485-493.

18. Schrijvers D, Samblanx H, Roila F. Erythropoiesis stimulating agents in the treatment of cancer patients: ESMO Clinical Practice Guidelines for use. Ann Oncol. 2010;21(Suppl 5):244-247

19. Carson JL, Grossmann BJ, Kleinmann S, et al. Red blood cell transfusion: a clinical practice guaidline from the AABB. Ann Intern Med. 2012;157: 49-58.

20. Eisterer W, Hussl C, Erb H, et al. Evaluating the transfusion rate with darbepoetin alfa 500 microg every 3 weeks in anemic cancer patients receiving chemotherapy. Cur Med Res Opin. 2011;27:355-363.

21. Canon JL, Vansteenkiste J, Hedenus M, et al. Transfusion risk in cancer patients with chemoterapy-induced anemia when initiating darbepoetin alfa therapy at a baseline hemoglobine level of $<9 / \mathrm{g} / \mathrm{dL}$ versus 9 to $10 \mathrm{~g} /$ $\mathrm{dL}$ versus $\geq 10 \mathrm{~g} / \mathrm{dL}$ : an exploratory analysis of a phase 3 trial. Med Oncol. 2011, doi: 10.1007/s12032-011-0103-x. 